\title{
Functional outcomes after sphincter-preserving surgeries for low-lying rectal cancer A review
}

\section{Eun Jung Park, Seung Hyuk Baik}

Division of Colon and Rectal Surgery, Department of Surgery, Gangnam Severance Hospital, Yonsei University College of Medicine, Seoul, Korea

Received: October 12, 2021

Revised: November 14, 2021

Accepted: November 17, 2021

Corresponding author:

Seung Hyuk Baik

Division of Colon and Rectal

Surgery, Department of Surgery,

Gangnam Severance Hospital,

Yonsei University College

of Medicine, 211 Eonju-ro,

Gangnam-gu, Seoul 06273, Korea

Tel: +82-2-2019-3378

E-mail:whitenoja@yuhs.ac

\section{ABSTRACT}

Sphincter preservation and organ restoration during rectal cancer surgery avoids permanent stoma creation and diminishes psychosocial damages. However, decreased rectal volumes and sphincter dysfunction-including pelvic nerve damage-results in low anterior resection syndrome, as well as urinary and sexual dysfunction after rectal resection. Bowel habit changes such as fecal incontinence, fecal urgency, frequent bowel movements, clustered stools, and difficulties in bowel emptying can be treated using medications, pelvic floor rehabilitation, sacral neuromodulation, or neorectal reservoir reconstruction. Pelvic nerve damage resulting from superior and inferior hypogastric plexi during sphincter-preserving rectal cancer surgery can induce urologic and sexual dysfunctions. Preoperative voiding difficulty, perioperative blood loss, and autonomic nerve injury are considered independent risk factors for postoperative urinary dysfunction. Retrograde ejaculation and erectile dysfunction, female dyspareunia, and vaginal dryness are manifestations of sexual dysfunction resulting from autonomic nerve injury during rectal cancer surgery. Multifactorial causes for functional outcomes after sphincter-preserving surgeries are considered to improve patient's quality of life with acceptable oncologic outcomes in the treatment of rectal cancer patients.

Keywords: Fecal incontinence; Postoperative complications; Rectal neoplasms; Risk factors; Sexual dysfunction, physiological
This is an Open Access article distributed under the terms of the Creative Commons Attribution Non-Commercial License (https:// creativecommons.org/licenses/ by-nc/4.0/).

\section{INTRODUCTION}

In recent decades, rectal cancer surgery has advanced with the development of surgical techniques and multimodal treatments. The application of total mesorectal excision (TME) for rectal cancer has made it possible to perform anatomical dissection in the pelvis and markedly reduce the local recurrence rate [1-3]. In addition, concomitant chemotherapy with preoperative radiotherapy followed by curative resection has decreased local recurrence and enhanced anal sphincter preservation in patients with locally advanced low rectal cancer [4-6]. Ultra-low anterior resection (LAR) with dissection along intersphincteric planes may facilitate sphinc- 
ter-preservation during rectal cancer surgery. Abdominoperineal resection (APR) was the gold standard treatment of patients with tumor infiltrations of rectal muscular layers and perirectal tissues in distal one-third low-lying rectal cancers; however, sphincter-preserving surgery using intersphincteric resection (ISR) is regarded as an alternative to APR, based on safe distal resection margins and equivalent oncologic outcomes $[7,8]$. It is currently acceptable that a $1-\mathrm{cm}$ distal resection margin is sufficient despite concerns about tumor cell spread within mesorectal lymph nodes within less than 5 $\mathrm{cm}$ and the rule of $2 \mathrm{~cm}$ distal margin [9-11]. The local recurrence rate after sphincter-preserving surgery ranges from $4 \%$ to $13 \%$, which is comparable with that of previous surgical techniques [12-14].

Rectal resection with sphincter preservation and organ restoration is advantageous, as it avoids a permanent stoma and diminishes psychosocial damage. However, decreased rectal volumes and sphincter dysfunction including pelvic nerve damage are worrisome features after sphincter-preserving low rectal cancer surgery. Herein, we evaluated the functional outcomes with a focus on bowel, urogenital, and sexual dysfunctions after sphincter-preserving surgery for low rectal cancer.

\section{BOWEL DYSFUNCTION}

\section{Physiological characteristics of the rectum}

The rectum is a storage reservoir of feces. Normal defecation processes are caused by a stimulation of rectal distention due to rectal filling and the recto-anal inhibitory reflex (RAIR) [15]. The coordination of both anal sphincter and pelvic floor muscles is important for fecal evacuation from the rectum. The internal sphincter, whose function is mediated by parasympathetic nerves, maintains anal closure with a continuous tonic contraction [16]. The external sphincter, innervated by the branches of pudendal and inferior rectal nerves, is controlled voluntarily. Internal sphincter relaxation and external anal sphincter activation with decreased puborectalis sling contraction are needed for defecation. Anorectal structure activation and nerve innervation near the rectum normally occur simultaneously. However, both structural and neurologic damages after sphincter-preserving surgery can change these mechanisms of defecation, thereby causing low anterior resection syndrome (LARS).

\section{Low anterior resection syndrome}

Patients with LARS have typical symptoms including fecal in-

\section{After sphincter-preserving rectal cancer surgeries}

Rectal

Decreased rectal volume

Loss of retrograde propulsion

Neorectum

Neurologic/structural damage of anal sphincter Decreased neorectal compliance

Pelvic floor

Spastic hypermotility of neorectum

Denervation of the pelvic floor

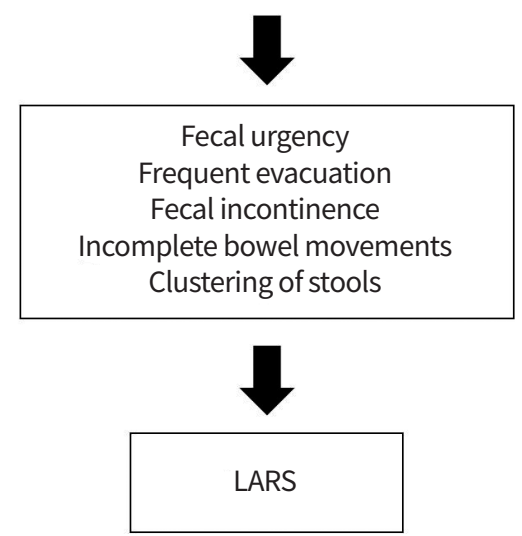

Fig. 1. Pathophysiology of low anterior resection syndrome (LARS).

continence, fecal urgency, frequent bowel movements, clustered stools, and difficulties in bowel emptying after rectal resection [17]. Moreover, these patients present with daily episodes of various symptoms ranging from incontinence to constipation. Patients with LARS may present with the following symptoms: frequent and multiple daily fecal evacuations; urge to defecate more than four times within 1 or 2 hours, with small amounts of feces; continence disorders; and urgency, with difficulties in retaining fecal emission for more than 15 minutes after a rectal sensation to defecate $[18,19]$. LARS can be accompanied by pelvic pain, tenesmus, defecation difficulties, dyspareunia, and skin irritation from frequent defecation (Fig. 1). Previous studies have reported that $30 \%$ to $90 \%$ of patients who undergo sphincter-preserving surgery experience LARS $[20,21]$. The symptoms of LARS occur more frequently within 4 to 5 months after surgery, and tend to improve within 1 to 2 years $[22,23]$. However, the incidence and symptoms of LARS reported by previous studies depend on the study design, LARS definition used, and study follow-up period.

Hitherto, the pathophysiology of LARS remains unclear, as its etiology is multifactorial. However, the reduced size of the remnant rectum and the presence of mechanical injuries in the anal canal correlate with long-term fecal soiling and incontinence. A relatively higher rectal reservoir pressure with 
decreased anal sphincter function can result in frequent stool soiling. Kakodkar et al. [22] reported that a reduced rectal reservoir capacity, a shortened high-pressure zone, and RAIR loss are associated with LARS occurrence. Moreover, a decreased rectal capacity compliance-that is related to pressure changes resulting from rectal volume changes-is associated with stool frequency and bowel urgency [24]. In addition, the hypermotility of the neorectum, which is reconstructed from the left colon, may cause fecal incontinence and bowel dysfunction. These structural damages of anal sphincter muscles and decreases the size of the rectal wall; more so, denervation may result in LARS after rectal surgery [19]. Eldamshety et al. [25] reported that the incidences of fecal incontinence, hypotonic anal function, and slightly hypotonic anal function were $10.6 \%, 8.6 \%$, and $26.1 \%$, respectively, based on their assessment using a per anal examination scoring system in patients with anorectal cancer who underwent TME with ISR.

\section{Assessment and questionnaires of LARS}

The assessment of patients with LARS begins with detailed history taking. Thereafter, patients undergo physical examination and evaluation using instrumental methods such as anal manometry [26]. The Wexner incontinence score, the Fecal Incontinence Severity Index (FISI), and the St. Marks' Fecal Incontinence Grading Score have been used to assess incontinence and urgency in patients with LARS [27-29].

The Wexner score (Cleveland Clinic Incontinence Score) is widely used to evaluate fecal incontinence and defecatory function. It is used to assess solid stool, liquid stool, flatus, the use of wearing pad, and lifestyle alteration [27]. Each item is scored from 0 to 4 based on the frequency. Clinically, a patient with a Wexner score that exceeds 8 to 9 is considered to have fecal incontinence.

The FISI is composed of a matrix of type and frequency based on the components of fecal incontinence $[18,28]$. Four types of incontinence are assessed: gas and mucus, as well as liquid and solid stool incontinence. The frequency of incontinence is classified with respect to five periods: $\geq 2$ times a day; once a day; $\geq 2$ times a week; once a week; and one to three times a month. While Wexner score have the same weight for stool types, FISI has a scoring system to weigh the patient's symptoms. However, both the Wexner score and FISI have several drawbacks; they cannot be used to evaluate other symptoms such as urgency and difficulties with rectal emptying in patients with LARS. The Memorial Sloan-Kettering Cancer Center Bowel Function Instrument
(MSKCC BFl; 2005) is the first questionnaire that was used to evaluate bowel function after sphincter-preserving rectal cancer surgery [30]. It contains 18 questions related to bowel function, which have five categories of answers: always, most of the time, sometimes, rarely, and never. The 18 questions related to bowel function are divided into subscales: six, four, and four questions for the frequency, dietary, and urgency/soiling subscales, respectively; moreover, there are five individual questions. The MSKCC BFI score is advantageous in that it provides a detailed and comprehensive assessment of patients with LARS; nonetheless, the questions are too long and the scoring system is difficult.

Notwithstanding, Emmertsen and Laurberg [31] proposed a LARS score questionnaire (LARS score; 2012), which was developed and validated in Danish patients with rectal cancer; and is a symptom-based scoring system for patient who undergo LAR. The score comprises five important items: incontinence for flatus, incontinence for liquid stool, stool frequency, clustering, and urgency. The Danish patients were divided into three groups with scores ranging from 0 to 42 points based on the severity of LARS: no LARS ( 0 to 20 points), minor LARS (21 to 29), and major LARS (30 to 42).

The LARS score was associated quality of life (QoL), and was significantly different in patients with a history of radiotherapy, tumor location less than $5 \mathrm{~cm}$, and who underwent complete TME. Urgency and clustering had the highest weights among the items in the LARS score, and therefore affected patient QoL. The main strength of the LARS score is that it is concise and easily reflects patient QoL. However, the measurement scope of the LARS score is smaller than that of the MSKCC BFI score. The LARS score is translated into several languages such as English, German, and Swedish. In addition, Kim et al. [32] validated the LARS score questionnaire in Korean patients after translating the LARS questionnaire from the English to the Korean language. In their assessment, the LARS score showed discriminative validities between groups in terms of sex (male vs. female, 29 vs. 25, $P=0.014$ ), tumor location ( $\leq 8 \mathrm{~cm}$ vs. $>8 \mathrm{~cm}, 29$ vs. $29, \mathrm{P}=0.021$ ), and radiotherapy use (radiotherapy vs. no radiotherapy, 32 vs. $24, P=0.001$ ). The LARS score was also related to patient QoL, which corroborated with the results of similar studies conducted in Europe and Japan.

\section{Risk factors of LARS after sphincter-preserving surgery} LARS is known to be associated with young age, as well as low rates of anastomosis, neoadjuvant chemotherapy use, and anastomotic leakage in patients who underwent sphinc- 
ter-preserving surgery [33]. A large population-based Danish study, which examined patients who developed LARS after curative resection of rectal cancer, reported that neoadjuvant chemotherapy use (regardless of the short- or long-course protocol) and TME were strong independent factors for major LARS (LARS score $\geq 30$ ) [34].

Radiation therapy is an independent factor affecting the severity of LARS [35-37]. A Dutch TME trial that evaluated the long-term effects of preoperative radiotherapy using $5 \times 5$ Gy found that irradiated patients have higher rates of fecal incontinence than non-irradiated patients ( $62 \%$ vs. $38 \%$, $\mathrm{P}<0.001$ ) [38,39]. In addition, in 2017, Qin et al. [40] reported that preoperative long-course radiotherapy, lower-third rectal cancer, and rectal wall thickening after radiotherapy are strong predictors of severe bowel dysfunction after LAR. Bondeven et al. [37] evaluated 125 patients who underwent sphincter-preserving surgery for rectal cancer, and found that a lower length of the remnant rectum from the anal verge (as the level of anastomosis) and preoperative chemoradiotherapy strongly affect the severity of bowel dysfunction. The irradiated remnant rectum at the distal part of anastomosis may affect the severity of bowel dysfunction because the remnant rectum tends to experience a decrease in neorectal sensitivity with changes such as tissue fibrosis and visceral afferent nerve impairment. Parc et al. [41] reported that preoperative radiotherapy might result in poorer functional outcomes after LAR with colo-anal anastomosis, although the overall morbidity did not increase in their study. Patients who underwent neoadjuvant radiotherapy had higher bowel movement frequencies per day and total daily bowel movement until 4 months post-radiotherapy. The rates of fecal urgency were greater at most time points during the study period in irradiated than non-irradiated patients.

The Danish study also found the female sex, younger age ( $\leq 64$ years), and anastomotic leakage as risk factors of LARS after rectal surgery [34]. It is unclear that younger age is associated with LARS occurrence. In contrast, Kornmann et al. [42] evaluated patients in two Dutch hospitals, and reported that patient QoL was related to LARS occurrence in elderly ( $\geq 70$ years) female patients who underwent sphincter-preserving rectal cancer surgery. The female sex was a risk factor for LARS probably due to obstetric trauma and pelvic floor disorders resulting from vaginal deliveries [43]. In their study, the male sex showed no differences in fecal incontinence quality of life (FIQOL) scores between younger ( $<70$ years) and elderly patients; nevertheless, elderly women showed a deterioration of FIQoL subscale scores for coping/behavior and depression/self-perception than younger women.

Long-term survivors with anastomotic leakage were more predisposed to developing LARS in the Danish study. A French case-control study evaluated patients undergoing laparoscopic sphincter-preserving rectal cancer surgery, and demonstrated that patients in the anastomotic leakage group showed higher LARS scores than those in the control group (30 vs. 27 , $P=0.02$ ) [44]. Anorectal and urogenital dysfunctions deteriorated in patients with symptomatic anastomotic leakages such as pelvic sepsis, the presence of recto-vaginal fistula, or pus drainage from the pelvis. In addition, Kim et al. [33] evaluated the relationship between the severity of LARS and anastomotic leakage in patients who underwent LAR for rectal cancer. The ratio of major LARS score in patients with anastomotic leakage group were higher than control group (37.8\% vs. $11.1 \%, P<0.001)$. Anastomotic leakage is thought to induce negative changes in bowel functions due to inflammation scar tissue formation in the pelvic cavity, thereby causing incontinence and urgency [45]. However, there is a paucity of studies regarding the occurrence of LARS after anastomotic leakage; the effect of a permanent stoma and the confounding risks of morbidities after sphincter-preserving surgery in patients with postoperative anastomotic leakage should be considered.

\section{Association between surgical technique and LARS occurrence}

With improvements in minimally invasive surgical techniques, laparoscopic and robotic surgeries-with comparable oncologic outcomes-are currently used as alternatives to conventional open surgery in the treatment of rectal cancer [46-48]. Specifically, colorectal surgeons are attracted by the magnified view that permits sharp dissection in a narrow pelvic cavity. Moreover, patients who undergo laparoscopic rectal cancer surgery have better QoLs than those who undergo open surgery [49,50]. Robotic TME for rectal cancer is associated with lower conversion rates, improved genitourinary functions, and comparable oncologic outcomes [51-54]. Recently, transanal total mesorectal excision (TaTME) was developed to overcome the difficulties encountered during procedures for mid or low rectal cancer that is located below $10 \mathrm{~cm}$ from the anal verge. TaTME has a clinical advantage, as it results in precise dissection with improved surgical views. A previous study showed no significant difference for TME quality of specimens and CRM involvement between TaTME and robotic TME [55]. In a meta-analysis of studies evaluating 
patient QoL after TaTME, bowel dysfunction was related with LARS occurrence. However, there was no difference in the functional outcomes between TaTME and laparoscopic TME [56]. Koedam et al. [57] reported that deterioration of all questionnaires was observed at 1 month, and improved at 6 months after TaTME, with acceptable functional outcomes and QoL. On the other hand, van der Heijden et al. [58] demonstrated functional impairments after TaTME in Dutch patients with rectal cancer. Major LARS was reported in $73.3 \%$ of patients with bowel dysfunction resulting in fecal incontinence. Further studies are warranted to evaluate patient QoL after TaTME.

\section{Treatment of LARS: non-operative and operative methods \\ Medical therapy}

Medical treatment for LARS after rectal cancer surgery is based on the use of transit modifiers and the control of intestinal emptying. Bulking agents and high fiber diet can be used to control stool frequency and the clustering of stool. For diarrhea-predominant symptoms, anti-diarrheal agents such as loperamide or codeine can be used to decrease stool frequency and increase the resting pressure of the anal sphincter [15,59]. In addition, serotonin (5-hydroxytryptamine [5$\left.\mathrm{HT}_{3}\right]$ ) receptor antagonists are effective in the treatment of LARS, which is a diarrhea-predominant irritable bowel syndrome [60]. They decrease intestinal transit and intestinal hypermotility, which are related with urgency, frequency, and incomplete fecal evacuations. Furthermore, serotonin receptor antagonists reduce propagatory propulsions of the neorectum, thereby relieving symptoms related to the postoperative hypermotility of the neorectum. Small bowel bacterial overgrowth is found in $4 \%$ to $70 \%$ of patients with irritable bowel syndrome [61]. Antibiotics such as rifaximin or neomycin can be used to control small intestinal bacterial overgrowth in the remnant rectum. Retrograde colonic irrigation has been used to treat fecal incontinence and stool fragmentation, as the irrigation assists in fecal evacuation. Wexner scores are reportedly improved in patients with LARS after retrograde colonic irrigation; however, irrigation can potentially lead to colonic mucosa damage [62].

\section{Pelvic floor rehabilitation}

Pelvic floor rehabilitation is aimed at improving the support of pelvic structures and increasing the strength of autonomic pelvic contraction. The rehabilitation includes biofeedback therapy, pelvic floor muscle training, and rectal balloon train- ing [39]. Biofeedback therapy is useful to activate pelvic floor muscles via visual signals, and improve pelvic floor dyssynergia such as fecal incontinence or rectal evacuation disorders [63]. Biofeedback therapy can induce synchronous voluntary movements of the external anal sphincter and rectal sensation. According to Lee et al. [64], biofeedback therapy decreases the Wexner score and increases the rectal capacity in patients who developed LARS following rectal cancer surgery. A systematic review of studies on pelvic floor rehabilitation of patients who underwent LAR demonstrated improvements in fecal incontinence, stool frequency, and QoL [39]. More so, pelvic floor rehabilitation improves the Wexner score and anal manometry findings $[39,65,66]$.

\section{Sacral neuromodulation}

Sacral nerve stimulation (SNS) is a useful method to treat fecal incontinence; it involves anorectal function activation using low-voltage electrical stimulation of sacral spinal nerves. It may prolong colonic transit time and increase colonic storage capacity because antegrade and retrograde colonic activities are reduced and increased, respectively, during defecation $[67,68]$. A systematic review revealed that SNS had symptomatic benefits in patients with refractory LARS, with improvements in the Wexner and LARS scores [69]. In a French study, SNS for bowel dysfunction showed an overall success rate of $86 \%$, with a decrease in the Wexner and LARS scores in patients undergoing rectal resection, left hemicolectomy, or ileal-pouch anal anastomosis [70]. Permanent SNS device implantation reportedly has a long-term success rate of $74.4 \%$ [71], with a reduction in nocturnal clustering (3 to 0.5 episodes per night; 7 to 0.5 episodes per day; $P<0.01$ ) [71]. In addition, fecal urgency, nocturnal defecation, fragmentation, and soiling were significantly resolved after SNS in patients with LARS. Thus, SNS is a promising therapeutic method in patients who develop LARS after rectal cancer surgery.

\section{Neorectal reservoir reconstruction}

The rectum is a stool reservoir; decreased rectal volumes after LAR result in stool urgency, frequency, and incontinence. Thus, colonic reconstructions such as colonic J pouch anastomosis, transverse colostomy, and side-to-end colo-anal anastomosis have been developed to enhance neorectal reservoir function. In previous studies, colonic J pouch anastomosis improved stool frequency and the use of anti-diarrheal agents until 1 year compared with straight colo-anal anastomosis [72,73]. Fazio et al. [74] reported that a colonic J pouch anastomosis reduced the stool frequency and FISI in both 
early and late postoperative periods. In addition, the surgical and functional outcomes of transverse coloplasty and sideto-end colo-anal anastomosis were comparable to those of colonic J pouch anastomosis. However, in some studies, neorectal reservoir reconstruction did not improve LARS outcomes in the long term; the effects disappeared within 24 months postoperatively $[73,75]$. Stoma formation is the final LARS treatment modality after anastomosis failure.

\section{UROLOGIC AND SEXUAL DYSFUNCTION}

\section{Anatomy of pelvic nerves}

As reported, $20 \%$ to $40 \%$ of patients who undergo rectal cancer surgery develop urinary and sexual dysfunctions [76], mostly resulting from intraoperative pelvic autonomic nerve injury [53]. Sympathetic and parasympathetic nerves originate from L2-3 and S2-4 nerve roots, respectively, to form the pelvic plexus $[15,77]$. The superior hypogastric nerves from the preaortic plexus descend inferiorly and laterally, and join the splanchnic nerves of the S2-4 nerve roots to form the pelvic plexus [16]. In addition, careful dissection should be performed along the Denonvillier's fascia during rectal cancer surgery, in order to preserve autonomic nerves, because neurovascular bundles from the pelvic plexus are located anterior (10 o'clock and 2 o'clock directions) to the rectum. Nerve bundle damage from the superior and inferior hypogastric plexi during sphincter-preserving rectal cancer surgery can induce urologic and sexual dysfunction (Fig. 2).

\section{Urologic dysfunction}

Bladder dysfunction occurs in $30 \%$ to $70 \%$ of patients after rectal cancer surgery $[78,79]$. Sympathetic nerves are responsible for urinary continence, whereas parasympathetic nerves control detrusor muscle contraction and urethral relaxation. Injury to these pelvic nerves during rectal cancer surgery causes urologic dysfunction such as voiding dysfunction. The International Prostate Symptom Score (IPSS) and Bristol Female Lower Urinary Tract Symptom instrument are widely use to evaluate urinary dysfunction. Lange et al. [80] demonstrated that $30.6 \%$ of patients who undergo rectal cancer surgery develop long-term problems of bladder emptying. In addition, preoperative voiding difficulty, perioperative blood loss, and autonomic nerve injury are independent risk factors. A Dutch TME trial-a multicenter, randomized trialshowed long-term functional outcomes in patients who underwent TME for rectal cancer with or without preoperative radiotherapy [81]. After 5 years postoperatively, $38 \%$ of patients developed urinary incontinence, of whom $72 \%$ had normal urinary function preoperatively $[77,81,82]$.

Toritani et al. [83] reported the following risk factors of urinary dysfunction after autonomic nerve-preserving rectal cancer surgery: low rectal tumor, tumor diameter $\geq 4 \mathrm{~cm}$, operation time $\geq 240$ minutes, blood loss $\geq 300 \mathrm{~mL}$, and the presence of diabetes mellitus. In addition, women are more predisposed to developing urinary dysfunction than men after TME $[80,84]$. Surgery-induced anatomical changes in the bladder, pelvic floor muscles, and urethra may alter the functions of pelvic nerves around the levator ani muscles and trigger urinary continence. In addition, postoperative tissue inflammation, altered pelvic muscle anatomy, and difficulties with perineal relaxation may cause stress-induced bladder hyperactivity and reduced bladder contractility. Ro-

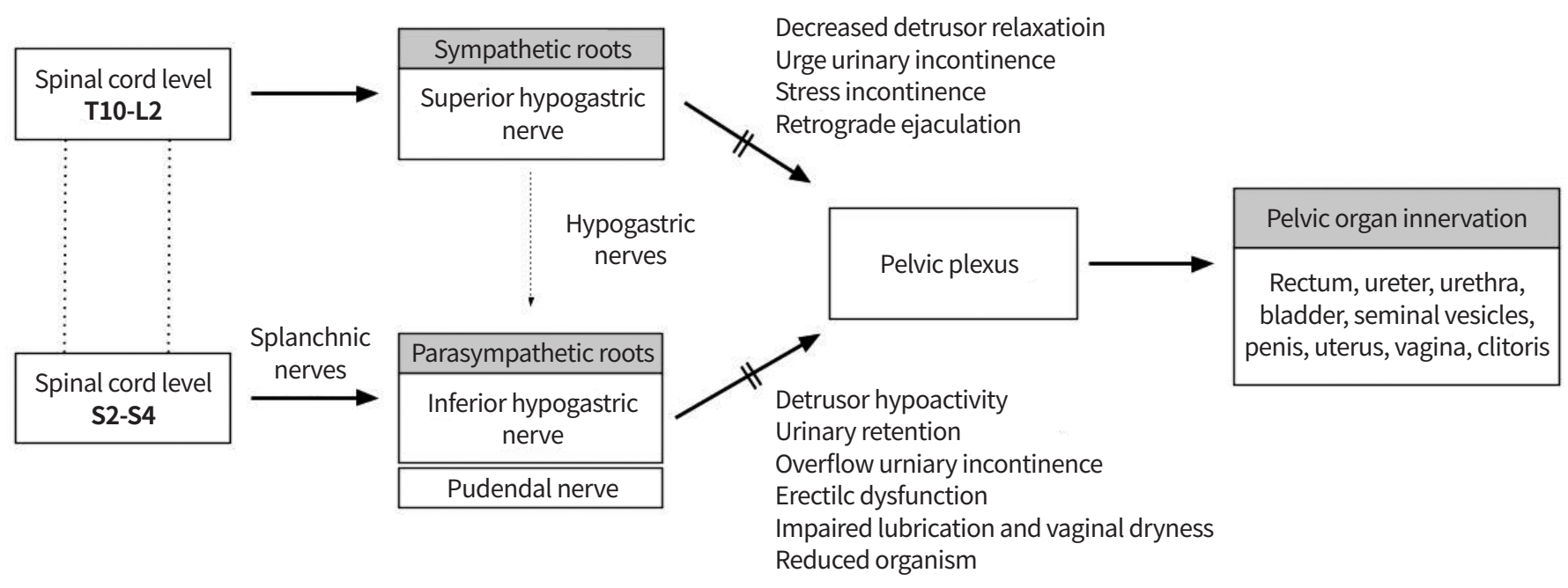

Fig. 2. The pelvic autonomic nerves system related with urologic and sexual dysfunction after rectal resection. 
botic rectal surgery results in improved urogenital function with pelvic nerve preservation compared with laparoscopic surgery, due to magnified and improved surgical visualization $[53,85]$.

\section{Sexual dysfunction}

Sexual dysfunction after rectal cancer surgery consists of erectile dysfunction and retrograde ejaculation in men; and dyspareunia, arousal, vaginal dryness, and orgasm in women. Retrograde ejaculation occurs when the superior hypogastric plexus or sympathetic nerves are injured, whereas erectile dysfunction, dyspareunia, and reduced vaginal lubrication occur due to inferior hypogastric nerve or pelvic plexus damage [86]. The International Index of Erectile Function and the Female Sexual Function Index are broadly used to assess sexual dysfunction after rectal cancer surgery.

Duran et al. [78] demonstrated that patients with tumors at the lower one-third of the rectum might be predisposed to developing urinary and sexual dysfunctions. A prospective cohort study of 948 patients who underwent rectal cancer surgery reported the following risk factors of sexual dysfunction: age $\geq 45$ years, tumor located below the peritoneal reflection, neoadjuvant radiotherapy, and APR [87]. Attaallah et al. [88] found that $76 \%$ of patients who underwent curative rectal cancer surgery had severe sexual dysfunction. Specifically, women showed higher rates of sexual dysfunction than men.

The quality of life after sphincter preservation surgery or abdominoperineal resection for low rectal cancer (ASPIRE) study compared the QoL of patients who underwent APR and sphincter-preserving surgery for low rectal cancer; patients who underwent APR had higher rates of worse body image, male sexual dysfunction (erectile dysfunction), and urinary dysfunction [89]. The National Surgical Adjuvant Breast and Bowel Project Randomized Trial R-04 showed that men who underwent APR had worse sexual satisfaction compared with those who underwent sphincter-preserving surgery [90]. In addition, patients who underwent APR had worse 1-year postoperative functional outcomes (evaluated using EORTC QLQ-CR38) than those who underwent sphincter-preserving surgery. Thus, sphincter-preserving surgery is considered an alternative to APR in the treatment of low rectal cancer, due to the comparable oncologic outcomes and acceptable QoL $[11,36]$.

Medications including tricyclic antidepressants, antihistamines, and decongestants such as phenylephrine can be used to treat retrograde ejaculation after rectal cancer surgery [91]. Tricyclic antidepressants enhance $\alpha$-adrenergic ac- tion, thereby increasing the pressure profile of the posterior urethra. Sildenafil citrate or vardenafil can be used to treat erectile dysfunction, because it increases blood flow to tissues near the nerves. Botulinum toxin, intracavernosal injections, inflatable penile implants, or vacuum devices can be used in cases of intractable medical therapy [81]. Topical estrogen can be applied in women with vaginal dryness and atrophy.

\section{CONCLUSION}

Sphincter-preserving rectal cancer surgery has acceptable oncologic outcomes with organ restoration. However, functional outcomes after rectal resection lead to bowel function impairment, resulting in LARS due to alternations in rectal capacity and damages of pelvic nerves. Urogenital and sexual dysfunctions are caused by intraoperative pelvic nerve injury and worsen patient's QoL. Therefore, surgeons should carefully perform sphincter-preserving rectal cancer surgery to ensure remnant bowel functional recovery and improve urologic and sexual dysfunction.

\section{CONFLICTS OF INTEREST}

No potential conflict of interest relevant to this article was reported.

\section{ACKNOWLEDGMENTS}

This study was supported by Basic Science Research Program through the National Research Foundation of Korea (NRF) funded by the Ministry of Science and ICT (NRF-2019 R1IA1A01058889 and NRF-2021R1A2C1012853), and a Faculty Research Grant of Yonsei University College of Medicine (6-2019-0179).

\section{ORCID}

Eun Jung Park https://orcid.org/0000-0002-4559-2690

Seung Hyuk Baik https://orcid.org/0000-0003-4183-2332

\section{AUTHOR CONTRIBUTIONS}

Conception or design: EJP, SHB.

Acquisition, analysis, or interpretation of data: EJP.

Drafting the work or revising: EJP.

Final approval of the manuscript: SHB. 


\section{REFERENCES}

1. Maurer CA, Renzulli P, Kull C, Kaser SA, Mazzucchelli L, Ulrich $A$, et al. The impact of the introduction of total mesorectal excision on local recurrence rate and survival in rectal cancer: long-term results. Ann Surg Oncol 2011;18:1899-906.

2. Heald RJ, Moran BJ, Brown G, Daniels IR. Optimal total mesorectal excision for rectal cancer is by dissection in front of Denonvilliers' fascia. Br J Surg 2004;91:121-3.

3. Kim SH, Bae KB, Kim JM, Shin JH, An MS, Ha TG, et al. Oncologic outcomes and risk factors for recurrence after tumor-specific mesorectal excision of rectal cancer: 782 cases. J Korean Soc Coloproctol 2012;28:100-7.

4. Sauer R, Becker H, Hohenberger W, Rodel C, Wittekind C, Fietkau R, et al. Preoperative versus postoperative chemoradiotherapy for rectal cancer. N Engl J Med 2004;351:173140.

5. Park IJ, Lee JL, Yoon YS, Kim CW, Lim SB, Yu CS, et al. Oncologic outcomes of organ preserving approaches in patients with rectal cancer treated with preoperative chemoradiotherapy. Ann Coloproctol 2019;35:65-71.

6. Rullier E, Goffre B, Bonnel C, Zerbib F, Caudry M, Saric J. Preoperative radiochemotherapy and sphincter-saving resection for $\mathrm{T} 3$ carcinomas of the lower third of the rectum. Ann Surg 2001;234:633-40.

7. Abraham NS, Davila JA, Rabeneck L, Berger DH, El-Serag HB. Increased use of low anterior resection for veterans with rectal cancer. Aliment Pharmacol Ther 2005;21:3541.

8. Kim MJ, Jeong SY, Park JW, Ryoo SB, Cho SS, Lee KY, et al. Oncologic outcomes in patients who undergo neoadjuvant chemoradiotherapy and total mesorectal excision for locally advanced rectal cancer: a 14-year experience in a single institution. Ann Coloproctol 2019;35:83-93.

9. Bujko K, Rutkowski A, Chang GJ, Michalski W, Chmielik E, Kusnierz J. Is the $1-\mathrm{cm}$ rule of distal bowel resection margin in rectal cancer based on clinical evidence? A systematic review. Ann Surg Oncol 2012;19:801-8.

10. Moore HG, Riedel E, Minsky BD, Saltz L, Paty P, Wong D, et al. Adequacy of 1-cm distal margin after restorative rectal cancer resection with sharp mesorectal excision and preoperative combined-modality therapy. Ann Surg Oncol 2003;10:80-5.

11. Kim CH, Yeom SS, Kwak HD, Lee SY, Ju JK, Kim YJ, et al. Clinical outcomes of patients with locally advanced rectal cancer with persistent circumferential resection margin invasion after preoperative chemoradiotherapy. Ann
Coloproctol 2019;35:72-82.

12. Martin ST, Heneghan HM, Winter DC. Systematic review of outcomes after intersphincteric resection for low rectal cancer. Br J Surg 2012;99:603-12.

13. Saito N, Ito M, Kobayashi A, Nishizawa Y, Kojima M, Nishizawa Y, et al. Long-term outcomes after intersphincteric resection for low-lying rectal cancer. Ann Surg Oncol 2014; 21:3608-15.

14. Akasu T, Takawa M, Yamamoto S, Ishiguro S, Yamaguchi T, Fujita S, et al. Intersphincteric resection for very low rectal adenocarcinoma: univariate and multivariate analyses of risk factors for recurrence. Ann Surg Oncol 2008;15: 2668-76.

15. Nocera F, Angehrn F, von Flue M, Steinemann DC. Optimising functional outcomes in rectal cancer surgery. Langenbecks Arch Surg 2021;406:233-50.

16. Lee JM, Kim NK. Essential anatomy of the anorectum for colorectal surgeons focused on the gross anatomy and histologic findings. Ann Coloproctol 2018;34:59-71.

17. Koda K, Yamazaki M, Shuto K, Kosugi C, Mori M, Narushi$\mathrm{ma} \mathrm{K}$, et al. Etiology and management of low anterior resection syndrome based on the normal defecation mechanism. Surg Today 2019;49:803-8.

18. Sarcher T, Dupont B, Alves A, Menahem B. Anterior resection syndrome: what should we tell practitioners and patients in 2018? J Visc Surg 2018;155:383-91.

19. Bryant CL, Lunniss PJ, Knowles CH, Thaha MA, Chan CL. Anterior resection syndrome. Lancet Oncol 2012;13:e4038.

20. Juul T, Ahlberg M, Biondo S, Espin E, Jimenez LM, Matzel $\mathrm{KE}$, et al. Low anterior resection syndrome and quality of life: an international multicenter study. Dis Colon Rectum 2014;57:585-91.

21. Cura Pales CG, An S, Cruz JP, Kim K, Kim Y. Postoperative bowel function after anal sphincter-preserving rectal cancer surgery: risks factors, diagnostic modalities, and management. Ann Coloproctol 2019;35:160-6.

22. Kakodkar R, Gupta S, Nundy S. Low anterior resection with total mesorectal excision for rectal cancer: functional assessment and factors affecting outcome. Colorectal Dis 2006;8:650-6.

23. Lai X, Wong FK, Ching SS. Review of bowel dysfunction of rectal cancer patients during the first five years after sphincter-preserving surgery: a population in need of nursing attention. Eur J Oncol Nurs 2013;17:681-92.

24. Chan CL, Lunniss PJ, Wang D, Williams NS, Scott SM. Rectal sensorimotor dysfunction in patients with urge faecal in- 
PRECISION AND FUTURE MIEDICINE

Functional outcomes after rectal cancer surgeries

continence: evidence from prolonged manometric studies. Gut 2005;54:1263-72.

25. Eldamshety O, Kotb S, Khater A, Roshdy S, Elashry M, Zahi MS, et al. Early and late functional outcomes of anal sphinctersparing procedures with total mesorectal excision for anorectal adenocarcinoma. Ann Coloproctol 2020; 36:148-54.

26. Dulskas A, Samalavicius NE. Usefulness of anorectal manometry for diagnosing continence problems after a low anterior resection. Ann Coloproctol 2016;32:101-4.

27. Jorge JM, Wexner SD. Etiology and management of fecal incontinence. Dis Colon Rectum 1993;36:77-97.

28. Vaizey CJ, Carapeti E, Cahill JA, Kamm MA. Prospective comparison of faecal incontinence grading systems. Gut 1999;44:77-80.

29. Ramage L, Qiu S, Yeap Z, Simillis C, Kontovounisios C, Tekkis $\mathrm{P}$, et al. Anorectal manometry versus patient-reported outcome measures as a predictor of maximal treatment for fecal incontinence. Ann Coloproctol 2019;35:319-26.

30. Temple LK, Bacik J, Savatta SG, Gottesman L, Paty PB, Weiser MR, et al. The development of a validated instrument to evaluate bowel function after sphincter-preserving surgery for rectal cancer. Dis Colon Rectum 2005;48:135365.

31. Emmertsen KJ, Laurberg S. Low anterior resection syndrome score: development and validation of a symptombased scoring system for bowel dysfunction after low anterior resection for rectal cancer. Ann Surg 2012;255:922-8.

32. Kim CW, Jeong WK, Son GM, Kim IY, Park JW, Jeong SY, et al. Validation of Korean version of low anterior resection syndrome score questionnaire. Ann Coloproctol 2020;36:83-7.

33. Kim S, Kang SI, Kim SH, Kim JH. The effect of anastomotic leakage on the incidence and severity of low anterior resection syndrome in patients undergoing proctectomy: a propensity score matching analysis. Ann Coloproctol 2021; 37:281-90.

34. Bregendahl S, Emmertsen KJ, Lous J, Laurberg S. Bowel dysfunction after low anterior resection with and without neoadjuvant therapy for rectal cancer: a population-based cross-sectional study. Colorectal Dis 2013;15:1130-9.

35. Juul T, Ahlberg M, Biondo S, Emmertsen KJ, Espin E, Jimenez LM, et al. International validation of the low anterior resection syndrome score. Ann Surg 2014;259:728-34.

36. Park IJ, Kim JC. Intersphincteric resection for patients with low-lying rectal cancer: oncological and functional outcomes. Ann Coloproctol 2018;34:167-74.

37. Bondeven P, Emmertsen KJ, Laurberg S, Pedersen BG.
Neoadjuvant therapy abolishes the functional benefits of a larger rectal remnant, as measured by magnetic resonance imaging after restorative rectal cancer surgery. Eur J Surg Oncol 2015;41:1493-9.

38. Peeters KC, van de Velde CJ, Leer JW, Martijn H, Junggeburt JM, Kranenbarg EK, et al. Late side effects of shortcourse preoperative radiotherapy combined with total mesorectal excision for rectal cancer: increased bowel dysfunction in irradiated patients. A Dutch colorectal cancer group study. J Clin Oncol 2005;23:6199-206.

39. Visser WS, Te Riele WW, Boerma D, van Ramshorst B, van Westreenen HL. Pelvic floor rehabilitation to improve functional outcome after a low anterior resection: a systematic review. Ann Coloproctol 2014;30:109-14.

40. Qin Q, Huang B, Cao W, Zhou J, Ma T, Zhou Z, et al. Bowel dysfunction after low anterior resection with neoadjuvant chemoradiotherapy or chemotherapy alone for rectal cancer: a cross-sectional study from China. Dis Colon Rectum 2017;60:697-705.

41. Parc Y, Zutshi M, Zalinski S, Ruppert R, Furst A, Fazio VW. Preoperative radiotherapy is associated with worse functional results after coloanal anastomosis for rectal cancer. Dis Colon Rectum 2009;52:2004-14.

42. Kornmann VN, Walma MS, de Roos MA, Boerma D, van Westreenen HL. Quality of life after a low anterior resection for rectal cancer in elderly patients. Ann Coloproctol 2016;32:27-32.

43. Andromanakos N, Filippou D, Skandalakis P, Papadopoulos V, Rizos S, Simopoulos K. Anorectal incontinence. pathogenesis and choice of treatment. J Gastrointestin Liver Dis 2006;15:41-9.

44. Hain E, Manceau G, Maggiori L, Mongin C, ProstA la Denise J, Panis Y. Bowel dysfunction after anastomotic leakage in laparoscopic sphincter-saving operative intervention for rectal cancer: a case-matched study in 46 patients using the Low Anterior Resection Score. Surgery 2017;161:102839.

45. Daams F, Monkhorst K, van den Broek J, Slieker JC, Jeekel $\mathrm{J}$, Lange JF. Local ischaemia does not influence anastomotic healing: an experimental study. Eur Surg Res 2013; 50:24-31.

46. Guillou PJ, Quirke P, Thorpe H, Walker J, Jayne DG, Smith AM, et al. Short-term endpoints of conventional versus laparoscopic-assisted surgery in patients with colorectal cancer (MRC CLASICC trial): multicentre, randomised controlled trial. Lancet 2005;365:1718-26.

47. Jayne DG, Guillou PJ, Thorpe H, Quirke P, Copeland J, Smith 
AM, et al. Randomized trial of laparoscopic-assisted resection of colorectal carcinoma: 3-year results of the UK MRC CLASICC Trial Group. J Clin Oncol 2007;25:3061-8.

48. van der Pas MH, Haglind E, Cuesta MA, Furst A, Lacy AM, Hop WC, et al. Laparoscopic versus open surgery for rectal cancer (COLOR II): short-term outcomes of a randomised, phase 3 trial. Lancet Oncol 2013;14:210-8.

49. Ng SS, Leung WW, Wong CY, Hon SS, Mak TW, Ngo DK, et al. Quality of life after laparoscopic vs open sphincter-preserving resection for rectal cancer. World J Gastroenterol 2013;19:4764-73.

50. Scarpa M, Erroi F, Ruffolo C, Mollica E, Polese L, Pozza G, et al. Minimally invasive surgery for colorectal cancer: quality of life, body image, cosmesis, and functional results. Surg Endosc 2009;23:577-82.

51. Kim HS, Kang JH, Yang SY, Kim NK. Long-term voiding and sexual function in male patients after robotic total mesorectal excision with autonomic nerve preservation for rectal cancer: a cross-sectional study. Surg Laparosc Endosc Percutan Tech 2020;30:137-43.

52. Park EJ, Cho MS, Baek SJ, Hur H, Min BS, Baik SH, et al. Long-term oncologic outcomes of robotic low anterior resection for rectal cancer: a comparative study with laparoscopic surgery. Ann Surg 2015;261:129-37.

53. Jang JH, Kim CN. Robotic total mesorectal excision for rectal cancer: current evidences and future perspectives. Ann Coloproctol 2020;36:293-303.

54. Jayne D, Pigazzi A, Marshall H, Croft J, Corrigan N, Copeland J, et al. Effect of robotic-assisted vs conventional laparoscopic surgery on risk of conversion to open laparotomy among patients undergoing resection for rectal cancer: the ROLARR randomized clinical trial. JAMA 2017;318: 1569-80.

55. Lee L, de Lacy B, Gomez Ruiz M, Liberman AS, Albert MR, Monson J, et al. A multicenter matched comparison of transanal and robotic total mesorectal excision for mid and low-rectal adenocarcinoma. Ann Surg 2019;270:1110-6.

56. van der Heijden J, Koeter T, Smits L, Sietses C, Tuynman JB, Maaskant-Braat A, et al. Functional complaints and quality of life after transanal total mesorectal excision: a meta-analysis. Br J Surg 2020;107:489-98.

57. Koedam TW, van Ramshorst GH, Deijen CL, Elfrink AK, Meijerink WJ, Bonjer HJ, et al. Transanal total mesorectal excision (TaTME) for rectal cancer: effects on patient-reported quality of life and functional outcome. Tech Coloproctol 2017;21:25-33.

58. van der Heijden J, van de Pas K, van den Broek F, van Diel- en F, Slooter GD, Maaskant-Braat A. Oncological and functional outcomes of transanal total mesorectal excision in a teaching hospital in the Netherlands. Ann Coloproctol 2021 Jun 29 [Epub]. https://doi.org/10.3393/ac.2020.00773. 0110.

59. Pucciani F. A review on functional results of sphincter-saving surgery for rectal cancer: the anterior resection syndrome. Updates Surg 2013;65:257-63.

60. Itagaki R, Koda K, Yamazaki M, Shuto K, Kosugi C, Hirano A, et al. Serotonin (5-HT3) receptor antagonists for the reduction of symptoms of low anterior resection syndrome. Clin Exp Gastroenterol 2014;7:47-52.

61. Distrutti E, Monaldi L, Ricci P, Fiorucci S. Gut microbiota role in irritable bowel syndrome: new therapeutic strategies. World J Gastroenterol 2016;22:2219-41.

62. Rosen H, Robert-Yap J, Tentschert G, Lechner M, Roche B. Transanal irrigation improves quality of life in patients with low anterior resection syndrome. Colorectal Dis 2011;13: e335-8.

63. Chiarioni G, Salandini L, Whitehead WE. Biofeedback benefits only patients with outlet dysfunction, not patients with isolated slow transit constipation. Gastroenterology 2005;129:86-97.

64. Lee KH, Kim JS, Kim JY. Efficacy of biofeedback therapy for objective improvement of pelvic function in low anterior resection syndrome. Ann Surg Treat Res 2019;97:194201.

65. Allgayer H, Dietrich CF, Rohde W, Koch GF, Tuschhoff T. Prospective comparison of short- and long-term effects of pelvic floor exercise/biofeedback training in patients with fecal incontinence after surgery plus irradiation versus surgery alone for colorectal cancer: clinical, functional and endoscopic/endosonographic findings. Scand J Gastroenterol 2005;40:1168-75.

66. Kim KH, Yu CS, Yoon YS, Yoon SN, Lim SB, Kim JC. Effectiveness of biofeedback therapy in the treatment of anterior resection syndrome after rectal cancer surgery. Dis Colon Rectum 2011;54:1107-13.

67. de Miguel M, Oteiza F, Ciga MA, Armendariz P, Marzo J, Ortiz H. Sacral nerve stimulation for the treatment of faecal incontinence following low anterior resection for rectal cancer. Colorectal Dis 2011;13:72-7.

68. Michelsen HB, Christensen P, Krogh K, Rosenkilde M, Buntzen S, Theil J, et al. Sacral nerve stimulation for faecal incontinence alters colorectal transport. Br J Surg 2008; 95:779-84.

69. Huang Y, Koh CE. Sacral nerve stimulation for bowel dys- 
PRECISION AND FUTURE MEDICINE

Functional outcomes after rectal cancer surgeries

function following low anterior resection: a systematic review and meta-analysis. Colorectal Dis 2019;21:1240-8.

70. Mege D, Meurette G, Vitton V, Leroi AM, Bridoux V, Zerbib P, et al. Sacral nerve stimulation can alleviate symptoms of bowel dysfunction after colorectal resections. Colorectal Dis 2017;19:756-63.

71. Ramage L, Qiu S, Kontovounisios C, Tekkis P, Rasheed S, Tan E. A systematic review of sacral nerve stimulation for low anterior resection syndrome. Colorectal Dis 2015;17: 762-71.

72. Brown CJ, Fenech DS, McLeod RS. Reconstructive techniques after rectal resection for rectal cancer. Cochrane Database Syst Rev 2008;2:CD006040.

73. Huttner FJ, Tenckhoff S, Jensen K, Uhlmann L, Kulu Y, Buchler MW, et al. Meta-analysis of reconstruction techniques after low anterior resection for rectal cancer. $\mathrm{Br} \mathrm{J}$ Surg 2015;102:735-45.

74. Fazio VW, Zutshi M, Remzi FH, Parc Y, Ruppert R, Furst A, et al. A randomized multicenter trial to compare long-term functional outcome, quality of life, and complications of surgical procedures for low rectal cancers. Ann Surg 2007; 246:481-8.

75. Heriot AG, Tekkis PP, Constantinides V, Paraskevas P, Nicholls RJ, Darzi A, et al. Meta-analysis of colonic reservoirs versus straight coloanal anastomosis after anterior resection. Br J Surg 2006;93:19-32.

76. Camilleri-Brennan J, Steele RJ. Quality of life after treatment for rectal cancer. Br J Surg 1998;85:1036-43.

77. Lange MM, Marijnen CA, Maas CP, Putter H, Rutten HJ, Stiggelbout AM, et al. Risk factors for sexual dysfunction after rectal cancer treatment. Eur J Cancer 2009;45:157888.

78. Duran E, Tanriseven M, Ersoz N, Oztas M, Ozerhan IH, Kilbas $Z$, et al. Urinary and sexual dysfunction rates and risk factors following rectal cancer surgery. Int J Colorectal Dis 2015;30:1547-55.

79. Quah HM, Jayne DG, Eu KW, Seow-Choen F. Bladder and sexual dysfunction following laparoscopically assisted and conventional open mesorectal resection for cancer. Br J Surg 2002;89:1551-6.

80. Lange MM, Maas CP, Marijnen CA, Wiggers T, Rutten HJ, Kranenbarg EK, et al. Urinary dysfunction after rectal cancer treatment is mainly caused by surgery. Br J Surg 2008; 95:1020-8.

81. Kapiteijn E, Marijnen CA, Nagtegaal ID, Putter H, Steup
WH, Wiggers T, et al. Preoperative radiotherapy combined with total mesorectal excision for resectable rectal cancer. N Engl J Med 2001;345:638-46.

82. Lange MM, van de Velde CJ. Urinary and sexual dysfunction after rectal cancer treatment. Nat Rev Urol 2011;8:517.

83. Toritani K, Watanabe J, Suwa Y, Suzuki S, Nakagawa K, Suwa $\mathrm{H}$, et al. The risk factors for urinary dysfunction after autonomic nerve-preserving rectal cancer surgery: a multicenter retrospective study at Yokohama Clinical Oncology Group (YCOG1307). Int J Colorectal Dis 2019;34:1697703.

84. Ulmsten U. Some reflections and hypotheses on the pathophysiology of female urinary incontinence. Acta Obstet Gynecol Scand Suppl 1997;166:3-8.

85. Tang X, Wang Z, Wu X, Yang M, Wang D. Robotic versus laparoscopic surgery for rectal cancer in male urogenital function preservation, a meta-analysis. World J Surg Oncol 2018;16:196.

86. Bohm G, Kirschner-Hermanns R, Decius A, Heussen N, Schumpelick V, Willis S. Anorectal, bladder, and sexual function in females following colorectal surgery for carcinoma. Int J Colorectal Dis 2008;23:893-900.

87. Li K, HeX, Tong S, Zheng Y. Risk factors for sexual dysfunction after rectal cancer surgery in 948 consecutive patients: a prospective cohort study. Eur J Surg Oncol 2021;47: 2087-92.

88. Attaallah W, Ertekin C, Tinay I, Yegen C. High rate of sexual dysfunction following surgery for rectal cancer. Ann Coloproctol 2014;30:210-5.

89. Kang SB, Cho JR, Jeong SY, Oh JH, Ahn S, Choi S, et al. Quality of life after sphincter preservation surgery or abdominoperineal resection for low rectal cancer (ASPIRE): a long-term prospective, multicentre, cohort study. Lancet Reg Health West Pac 2020;6:100087.

90. Russell MM, Ganz PA, Lopa S, Yothers G, Ko CY, Arora A, et al. Comparative effectiveness of sphincter-sparing surgery versus abdominoperineal resection in rectal cancer: patient-reported outcomes in National Surgical Adjuvant Breast and Bowel Project randomized trial R-04. Ann Surg 2015;261:144-8.

91. Arafa M, El Tabie O. Medical treatment of retrograde ejaculation in diabetic patients: a hope for spontaneous pregnancy. J Sex Med 2008;5:194-8. 